\title{
Web 3.0 and health librarians: an introduction
}

\author{
Allan Cho and Dean Giustini
}

\section{Key messages}

- Web 3.0 refers to the third decade of the Web from 20102020. Some experts believe we are entering a pre-Web 3.0 period.

- The current Web is characterized by global information overload and repetitive searching and browsing using Google.

- Debates about Web 3.0 are still somewhat theoretical, but a common theme is "developing an integrated web of data" based on sound principles of information systems design. Some experts say that the principles of librarianship should play a role in improving how the Web is organized.

- In 2008, semantic technologies are being used to solve information retrieval problems in bioinformatics, which may have specific applications in medicine. The term "Semantic Web" is occasionally used as a synonym for Web 3.0 (and vice versa), though some disagree with that usage.

- Health librarians should be thinking ahead about how to design better domain-specific search tools and user experiences (including virtual) in Web 3.0.

\section{Introduction}

This paper introduces some of the main concepts and principles of Web 3.0 for health librarians. In doing so, it aims to explore some of the issues and terminologies associated with the Web's projected development over the next 10 years, and at a level of generality that we hope will raise awareness and encourage debate. Many health librarians have recently adopted the underlying principles and social software tools of Web 2.0 into practice [1]. Can we be moving into the early stages of Web 3.0 already?

To answer that question, let's begin with some of the many conflicting definitions of Web 3.0. According to Wikipedia, "There is considerable debate as to what the term Web 3.0 means, and what a suitable definition might be" [2]. Web futurist Nova Spivack says that Web 3.0 refers to the third decade of the Web's development from 2010-2020 (Table 1). Spivack states that Web 3.0 is "...[a] more connected, open, and intelligent Web, using semantic technologies, distributed databases, natural language processing, machine

A. Cho. Reference Librarian, Humanities and Social Sciences, Walter C. Koerner Library, 1958 Main Mall, Vancouver, BC V6T 1Z2, Canada (e-mail: allan.cho@ubc.ca).

D. Giustini. Reference Librarian, Biomedical Branch Library, Gordon and Leslie Diamond Health Care Centre, 2775 Laurel Street, Floor 2, Vancouver, BC V5Z 1M9, Canada (e-mail: dean.giustini@ubc.ca). learning and machine reasoning..." [3]. A number of Internet experts say that we are already moving toward using the technologies that herald this new era [4]. But some librarians say that these definitions do little to clarify what Web 3.0 is (E. Barsky and G. Rowell, personal communication, 23 February 2008). One librarian blogger is vehement that Web versions do not (or should not) exist [5].

In 2007, the trade journal PC Magazine stated, "In case you missed it, the Web now has version numbers" [6]. We view the use of Web versions as simply a kind of shorthand. As the Web evolves, periods of time designated by numbers serve as useful guideposts in the digital age. Think of how terms like Generation X have entered the zeitgeist and how the Web has spawned terms like the Internet Generation (iGen). It seems natural to us to use these terms as tags or memes because they help to refer to a trend or a set of trends quickly. In fact, some futurists have already begun to list the features of the Web beyond its third generation to Web 4.0 [7]. Despite some misuse, versioning seems likely to continue for the foreseeable future.

What's important, in our view, are the Web 3.0 information trends that health librarians should be anticipating, watching, and thinking about for the future:

(1) The idea of transforming the Web into a large database

(2) Creating "information" pathways for artificial intelligence and machine-based reasoning

(3) Applying varied technologies of the Semantic Web to improve information retrieval

(4) Assimilating three-dimensional (3D), virtual, and simulated worlds into the Web experience [8]

The common theme here is a focus on information organization and retrieval. We are interested in these issues because they are so dominant in our work as health librarians. Although Web 3.0 and the Semantic Web have distinct connotations, we argue that both concepts point to the need for a sea change in the way that Web information is organized, described, and located. This similarity may explain why the two terms are often used interchangeably and (or) synonymously. Where possible, we try to make distinctions between Web 3.0 and the Semantic Web, but we too are grappling with a number of vague definitions.

\section{Everything is miscellaneous and fragmented}

To clarify Web 3.0 concepts, information retrieval seems a natural starting point for health librarians. Simply put, Web 
Table 1. Stages in the development of the Web.

\begin{tabular}{lll}
\hline Web 1.0 & Web 2.0 & Web 3.0 \\
1990-2000 & $2000-2010$ & $2010-2020$ \\
Read or write Web & Social Web & Semantic Web \\
\hline
\end{tabular}

3.0 - an extended, better version of the Web created over the next 10 years-is needed because of the problems we have in performing effective information retrieval. As many expert searchers know, cumulating the medical evidence via the Web has become increasingly difficult in an "everything-is-miscellaneous" universe [9]. For systematic reviews, health librarians must invest vast amounts of time and energy in locating relevant studies from multiple databases. There is often considerable hesitancy on the part of health librarians in doing systematic reviews because finding all studies on clinical interventions is so onerous. As health librarians, we would like to explore better methods of federated searching and metasearching in Web 3.0.

Some of the root causes of poor integration in information retrieval seem self-evident to us. As Svenonius writes, "The essential and defining objective of a system for organizing information is to bring like information together and to differentiate what is not alike" [10]. The current Web does an extremely poor job of bringing information together (co-location) and differentiating between closely related concepts (disambiguation). Another pernicious problem is how fragmented the biomedical literature has become; even meta-search tools such as the Trip Database and SumSearch cannot completely remedy the problems that health librarians face in conducting searches for a disseminated literature. While it is true that designing better systems of organization and using greater precision help, the information age has simply become too efficient in creating vast amounts of new medical knowledge.

Another problem for health librarians is that the Web is growing faster than we can possibly index it, given the proliferation of open access journals, self-archiving practices, and institutional repositories on the Web. That means we must investigate new systems of organization and automate some of our indexing processes. It means exploring the newest information technologies with an eye to their successful implementation outside our borders to knowledge-based organizations globally. The temptation is to rely on our venerable databases like MEDLINE or EMBASE for the most reliable information; however, we run the risk of becoming increasingly irrelevant or incompetent in the information age if we don't look beyond them.

With fewer health professionals using our print collections (many of whom want to locate information on the Web for themselves) [11], our attention should shift away from our physical libraries to "the Web as library". If we don't, our work may be overtaken by other information professionals, or perhaps our users themselves. To keep in step with changes needed over the long term, we must explore new ways of resolving information problems beyond our profession's limited ideologies [12].

\section{Information themes in Web $\mathbf{3 . 0}$}

A common library theme in this discourse is that Web 3.0 responds to a public service need and prompts information professionals to think about better principles of organization. In a 2007 British Medical Journal editorial, one health professional is quoted as saying that Web 3.0 should be where "pathways" for retrieval are supported by better descriptive standards [13]. To us, this notion sounds rather like the underlying purpose and architecture of MEDLINE. Further, these pathways are not unlike those we use to build our online catalogues. The importance of what documents mean and using words carefully to describe what they mean is an important aspect of indexing and the Semantic Web. Incidentally, "semantics" is a term derived from the Greek to give signs, meaning, or to make significant - a central goal of the Semantic Web.

In his landmark Scientific American paper, Sir Tim Berners-Lee said that semantic annotation of Web sites (adding metadata, for example) will create a global "Web of data'... and help to solve humankind's most complex problems" [14]. In a very real sense, we agree that this is also one of the primary goals of Web 3.0: moving toward integrated data, information, and knowledge. But not all information on the Web needs to be co-located, since so much of it is of questionable value. Why is this?

In recent years, the increase in worldwide production of information due to the participatory aspects of Web 2.0 has resulted in information overload. Spam, remix, and duplication are enormous problems. Is it any surprise that our users settle for something in Google ("a few good papers") when they could be doing more structured searching in MEDLINE? For our part, health librarians teach users how to find synthesized information in point-of-care tools like Cochrane, Clinical Evidence, and DynaMed. But how many physicians use these tools with any regularity? By missing important, seminal papers, physicians end up making decisions with incomplete or misleading evidence, leading to tragic results [15].

Some librarians point to an exclusive reliance on keyword searching as a source of many information problems. The lack of subject-oriented approaches is at the root of many of our end-users' search problems. But do they have many alternatives? As health librarians, we argue that keyword searching on the Web can only be recommended for "known item" searching or browsing (again, "a few good papers"). Google's drive to digitize any and all information and make it accessible is a noble goal. But much of this information is not described, indexed, or found easily. Will it be found? Or will that depend on luck and serendipity? Although free content may be very useful and convenient to access, digitization projects and open access journals do add to infooverload.

The logical first step in resolving overload is to isolate authoritative information. To move toward the Semantic Web, we will need to make the Web documents that contain meaningful information understandable to machines [16]. And let's put the evidence where end-users are searching. In Web 3.0, we literally need to tell computers what to do with containers of knowledge, the documents. This is achieved through rules-based inferences and telling computers what we want them to do with a certain set of documents. Changing how we organize knowledge will require a shift in our thinking. Some information professionals suggest that 
we begin to think of the open Web not as a place for ephemera but as a massive, searchable database [17].

\section{Controlled terms and ontologies}

By the way, while some health librarians develop their own sophisticated databases, most of us have not gone beyond creating basic relational databases by using simple tools like Microsoft Access. Typically, as reference librarians, we are asked to participate in creating index vocabularies and then to critique the interfaces used to extract information from the database. Hence, our focus has been on developing and (or) using subject-specific vocabularies to find things [18]. Even though we understand how terms and their variants are used in information retrieval, our experience is somewhat limited in building retrieval systems. This is one of the reasons why Google and search engine developers have usurped much of our work in the information age, not to mention vast fame and fortune.

For the billions of documents created in the future and stored on the Web, who will index this material? Will Google implement post-hoc controlled vocabularies as a means of organizing the world's information? Or will Google's hegemony in searching be challenged by semantic technologies? The National Library of Medicine (NLM) is working on automated indexing, which may be part of what we can use in the future [19]. Clearly, more librarian-led research and development need to be done.

Another challenge we anticipate is how to teach end-users about controlled vocabularies. Will we decentralize indexing by delegating the mountain of work to end-users as they publish their papers? Will health professionals want to learn how to index or create their own metadata? Is it reasonable to teach researchers how to index as part of information literacy? Health professionals have used keywords to annotate their journal articles for some time, so we can build on those efforts. If we are serious about finding better ways of doing things, health librarians will need to be creative.

With respect to grants, we believe that resource description will become an added step in applying for funding from the National Institutes of Health and the Canadian Institutes of Health Research in the future. Providing access to the published results of government-funded studies is now a requirement in both Canada and the United States [20,21]. Without the ability to apply controlled vocabularies and create metadata, researchers will be at a disadvantage as they self-archive their work. Where research is placed on the Web without proper metadata or in a form unreadable to computers, it will remain a fugitive literature-hidden in the deep Web [22]. At least one medical librarian suggests that a number of medical ontologies be used to create metadata, such as SNOMED and the Unified Medical Language System (UMLS) [23,24].

\section{Semantics in medicine}

The Semantic Web is linked to globalization as English has become the Web's lingua franca. A homogenized, universal language makes it easier to implement semantic technologies and controlled vocabularies, and promotes standards that help to clarify concepts. But even where Eng- lish is widely used, natural language variations creep into the vocabulary. As health librarians, we know that a consistent use of MeSH in MEDLINE will result in more accurate, complete searching. For example, doing MeSH searches for documents about the field of thoracic oncology or about the diseases lung cancer and small-cell lung neoplasia are easier when using a controlled vocabulary. Think about doing the same searches in Google and the variations of meaning and ambiguity that are encountered as a result of natural language terms.

Several semantic technologies have already been tested to disambiguate and clarify the confusion of overlapping concepts within millions of documents. These languageenabling technologies include an alphabet soup of acronyms, such as the RDF (Resource Description Framework), OWL (Web Ontology Language), FOAF (Friend of a Friend), and SKO (Simple Knowledge Organization System) [25-28]. The Web 2.0 tool, RSS (Really Simple Syndication), is also a descriptive framework [29] and enables RSS feeds to be read by all readers and aggregators despite potential incompatibilities.

Whether social tagging and folksonomies will result in useful data for use in Web 3.0 is an important question. A great deal of tagging work has already taken place on social bookmarking sites by consumers and patients. If we expect health professionals to learn more about applying labels to their work for the benefit of finding it later, the same expectation should be placed on general Web users. Of course, the problem with social tagging is its arbitrary nature as it is a kind of "indexing of the crowds". Marking your own work creates messy data and offers no controls for synonyms, homonyms, and spelling [16]. This is not a problem for a finite group of documents but becomes increasingly problematic as datasets increase. Moreover, the data created on tagging sites may be unusable unless health librarians can find ways to map it to an acceptable ontological framework.

Some health consumers and patients are using data language and ontologies in innovative ways [30]. Friend of a Friend (FOAF) is a decentralized social networking project (or system) that started in a grassroots way. Consumers have created a semantic vocabulary for describing people's names, ages, locations, jobs, and relationships, using them to reveal common interests. Users post information, photos, and video in all formats and connect them-something MySpace and Facebook cannot do on their own. More than one million individuals have already interlinked their FOAFs, including users of the blogging services Livejournal and TypePad. Health librarians should explore how to apply medical vocabularies to pre-existing datasets such as those on social networking and bookmarking sites, as they could potentially save considerable investments of time and resources.

\section{Web 3.0 as a searchable catalogue}

Semantic Web experts, especially those from computer science fields, can learn a great deal from library experts who are pushing the boundaries of automated cataloguing and indexing. In health libraries, technical experts at the NLM and the Canada Institute for Scientific and Technical Information (CISTI) are logical contacts. There are undoubt- 
edly many experts across the globe doing interesting work in this area, and we welcome their input.

A major library document currently in development that may have an impact on the direction of Web 3.0 is the soonto-be-released Anglo-American Cataloguing Rules (AACR3). By 2009, the Resource Description and Access (RDA) - the new name for AACR3 - will be a critical text for describing digital materials and establishing information principles well into the 21st century [31]. The issue of whether librarians can adjust their approach to Web 3.0 or be bound by their profession's "persnickety standards" [32] is open for debate. We suggest that health librarians enter into a discussion with their colleagues about RDA and plan for its implementation, not only within their institutions but with librarians in other disciplines and jurisdictions.

The Semantic Web has been described in terms that seem rather close in spirit to library databases. Searching in Web 3.0 has been described as "searching a large database" of millions of records, similar to our online catalogues. For the Semantic Web to work, it will need to describe items and provide multiple access points so that we can find them during our retrieval. In that sense, the Semantic Web will need to bring materials together in the same way that John Shaw Billings' Index Medicus brought journal literature together in the 19th century [33].

The catalogue metaphor can be taken further. Extensible markup language (XML) (used to format Web pages) and the efforts of the World Wide Web Consortium (W3C) point to new methods of presenting information [34]. The Online Computer Library Center (OCLC), long known for its contributions to descriptive frameworks, is working on better methods of describing objects and their intellectual content through the Dublin Core Project [35]. Bibliographic records for commonly held books and information sources are typically obtained through the Z39.50 standard; RDF technologies merely build on those organizational principles from our print-based library culture. But there is a sense that the two groups-library professionals and semantic technologists - do not communicate or see their potential synergies.

If libraries expect to participate in Web 3.0, our new cataloguing code, the Resource Description and Access (RDA), could play a prominent role. Libraries have a long history of data-sharing using consensus exchange standards and protocols. However, we discern some challenges ahead with RDA. Current standardization has become a "straightjacket" in response to changes in the digital landscape. Our legacy tools, such as MeSH, LCSH, and LCC, are difficult to apply outside of AACR2 and MARC-based records [36]. Some librarians argue that the next generation of library vocabularies should be "webified" [37]. Unless the new AACR developers can shift focus and find a way to work with professionals outside their field of expertise, there may be no significant change to how librarians will implement the code in Web 3.0.

Members from the Dublin Core Metadata Initiative and the RDA Joint Steering Committee produced a statement recently to ensure that the library community strives to collaborate on a metadata standard, one fully compatible with emerging Web architectures [38]. Developing controlled thesauri compatible with those on the Semantic Web is a positive but preliminary step as we move forward into Web 3.0.

\section{The Semantic Web in bioinformatics}

Semantic technologies are already being used on the Web particularly in the area of bioinformatics [39]. Retrieving relevant biomedical information from numerous databases is difficult owing to many different formats and data distribution across systems. The public and private network protocols that bioinformaticians encounter do not always work together and the interfaces used to filter information are often dissimilar. But somehow bioinformatics professionals have found a way to bring all of this data together using Semantic Web technologies. Think of the information derived from biomedical data mining as semantic mashups, a merging of tools that were formerly incompatible but now work together [40].

The NLM has designed a way to co-relate genome data with disease information in PubMed. Three bioinformatics tools-Entrez Gene, Online Mendelian Inheritance in Man, and the Gene Ontology - are used to look at genomes and disease information in tandem [41]. The bridging of genotypes and phenotypes in these resources normally requires manual effort or the development of customized software to process information. However, RDF was used to integrate these resources and enables seamless access to them as a unified resource [42].

WikiProteins is an important and exciting bioinformatics project; it incorporates annotation built by a community of scientists into a semantic framework [43]. In targeting scientists, Wikiproteins has potential application in several biomedical disciplines. It plans to import data from the world's leading biological databases such as PubMed and UniProt. Entries for every gene will contain relevant data such as its functional domains, areas of expression, and publications that discuss it. The merging of these databases yields more than two million relationships and five billion relationship pairs.

These examples of how semantic technologies can be used to further biomedical knowledge provide a glimpse into what is possible, where disparate sources of information can be brought together and viewed from new perspectives.

\section{Open access and data in Web $\mathbf{3 . 0}$}

Unless commercial interests overtake it, the Semantic Web should be an open space where previously incompatible systems work together. However, we believe that Web technologies are outpacing the legislation passed to control them. Openness and accessibility are not absolutes and need to be controlled. Confidential data, for example, will need to be protected in Web 3.0. Copyright concerns will obviously be front and centre in this emerging digital space. The restrictions imposed by copyright already inhibit access, and information retrieved in any future Web context may not be fully accessible owing to copyright. A good example of limited or reduced access because of copyright is the snippets feature in Google Books and Amazon.

The Google Health project and Microsoft's HealthVault may test society's tolerance for pushing the boundaries of accessible personal health information. Because accessing health information online can compromise patient confidentiality and privacy, openness on the Web will be a constant source of tension in Web 3.0. Consider that any digital activ- 
ity can be recorded and used for commercial purposes or marketing. The promise of Web 3.0 can quickly turn to intrusion: Do we want private medical information to be archived and fully searchable just because the technology makes it possible?

An added tension that tests public-private boundaries is information stored on social networking sites. Recently, Facebook gave permission to Google to crawl the member pages of its site [44]. What are the consequences of technological intrusions into the private realm? Machine-based intrusions into our lives will be a flashpoint in the development of the Semantic Web. Building a single searchable Web database comes with compromises to our privacy as crawling tools go deeper into databanks that hold information about us. Health librarians should work with legislators to find a balance of protections and freedoms in this potentially rich but volatile place.

\section{Conclusions}

In the past decade, Web searching has been almost singlehandedly dominated by the popularity of Google, the PageRank algorithm, and repetitive retrieval practices [45, 46]. Do we really need to search across the entire Web for each search query? Is that an efficient use of computer power? In order for librarians to find a way to change this, we can take steps to learn about new Web technologies in development and get more involved in the debate about their application in the information age. A first step may be to articulate our concerns about the Web's future through our national associations, professional journals, and personal weblogs.

Web 2.0 has ushered in an exciting time for health librarians. This short period has been a source of knowledgecreation and experimentation on an unprecedented scale but marked by information overload and poor findability. Health librarians need to advocate for (and devise) better methods of access over the next 10-15 years. Leading to reliable medical evidence has become a focus for many librarians as we see our end-users struggle to find the information they need. In Web 3.0, this problem will only worsen as the Internet scales up in size to a trillion or more documents [47].

As health librarians, we need to articulate a vision for change and find a secure place for ourselves in the digital age, or we may be left behind. A new Web built on the principles of librarianship would look vastly different from the Web we experience today. The Semantic Web could potentially be a place where much of the knowledge of librarians (and health service workers) can be built into the Web itself [48]. One of the remarkable things about semantic technologies is that they will probably not affect the look or feel of our "Web experiences", and may even perform their tasks without our end-users' knowledge. In other words, our users will likely be unaware of any filters or tools we have created to organize and connect the vast networks of information across the world. This could be important given our users' growing expectations for seamless delivery in the information age and their demands for instant access to handheld technologies. In any case, how we deliver those services to health care professionals while implementing the newest Web technologies will require constant adaptation as we move into Web 3.0.

\section{References}

1. Kamel Boulos MN, Wheeler S. The emerging Web 2.0 social software: an enabling suite of sociable technologies in health and health care education. Health Info Libr J. 2007 Mar;24(1):2-23.

2. Web 3.0. Wikipedia. 2008 Feb 20 [cited 2008 Feb 24]. Available from http://en.wikipedia.org/wiki/Web_3.

3. Spivak N. Web 3.0 - the best official definition imaginable [weblog]. 2007 Oct 4 [cited 2008 Feb 24]. Available from http://novaspivack.typepad.com/nova_spivacks_weblog/2007/10/ web-30----the-a.html

4. Berners-Lee T. The Semantic Web road map. 1998. World Wide Web (W3) Consortium [Web site] [cited 2008 Feb 24]. Available from http://www.w3.org/DesignIssues/Semantic.html.

5. Rothman D. Disliking "Web 2.0" and hating "Web 3.0" [weblog] [cited 2008 Feb 24]. Available from http://davidrothman.net/ 2008/01/08/disliking-web-20-and-hating-web-30/.

6. Metz C. Web 3.0. PC Magazine. 2007 March 8 [cited 2008 Feb 24]. Available from http://www.pcmag.com/article2/0, 1759,2102852,00.asp.

7. Pemberton S. Web 4.0: start planning now. A talk to the World Wide Web Consortium. 2006 Aug [cited 2008 Feb 24]. Available from http://www.w3.org/2006/Talks/06-08-steven-web40/.

8. Antoniou G, Van Harmelen F. A Semantic Web primer. MIT Press; 2004 Apr [cited 2008 Feb 19]. Available from http://www.ics.forth.gr/isl/swprimer/.

9. Weinberger D. Everything is miscellaneous: the power of the new digital disorder. New York: Times Books; 2007.

10. Svenonius E. The intellectual foundation of information organization. Cambridge: MIT Press; 2000.

11. Kaplan R, Steinberg M, Doucette J. Retention of retrospective print journals in the digital age: trends and analysis. $J$ Med Libr Assoc. 2006 Oct;94(4):387-93, e198-200.

12. Campbell DG, Brudin M, Maclean G, Baird, C. Everything old is new again: finding a place for knowledge structures in a satisficing world. In: Tennis JP, editor. Proceedings of the North American Society for Knowledge Organization [cited 2008 Feb 24]. Available from http://dlist.sir.arizona.edu/1896.

13. Giustini D. Web 3.0 and medicine: make way for the Semantic Web. BMJ. 2007;335(7633):1273-74.

14. Berners-Lee T, Hendler J, Lassila O. The Semantic Web. Sci Am. 2001;284(5):34-45.

15. Johns Hopkins University and Johns Hopkins Health Care System. Actions taken to strengthen research oversight at Johns Hopkins. 2001 [cited 2008 Feb 24]. Baltimore, Md.: Johns Hopkins University. Available from http://www.hopkinsmedicine. org/press/2001/AUGUST/actionplan.htm.

16. Cho A, Giustini D. The Semantic Web as a large, searchable catalogue: a librarian's perspectives. The Semantic Report. 2007 Oct 2 [cited 2008 Feb 24]. Available from http://www. semanticreport.com/index.php?option=com_content\&task=view \&id $=52 \&$ Itemid $=40$

17. Shadbolt N, Hall W. The Semantic Web revisited. IEEE Intelligent Systems. 2006 May/June [cited 2008 Feb 24]:96-101. 
Available from http://eprints.ecs.soton.ac.uk/12614/1/Semantic _Web_Revisted.pdf.

18. Adams K. The Semantic Web: differentiating between taxonomies and ontologies. Online. 2002;26(4):20-3.

19. Humphrey SM. Automatic indexing of documents from journal descriptors: a preliminary investigation. J Am Soc Info Sci. 1999 June;50(8):661-74.

20. National Institutes of Health. Public Access Policy [cited 2008 Feb 24]. Available from http://publicaccess.nih.gov/.

21. Canadian Institutes of Health Research. CIHR's Policy on access to research outputs in now in effect [cited 2008 Feb 24]. Available from http://www.cihr-irsc.gc.ca/e/35683.html.

22. Schmidt K, Shelburne WA, Vess D. Fugitive literature: approaches to selection, access and collection development in the Web world [cited 2008 Feb 24]. Available from http://works. bepress.com/cgi/viewcontent.cgi?article $=1000 \&$ context=karen schmidt.

-23. Slaughter L, Soergel D, Rindflesch T. Semantic representation of consumer questions and physician answers. Int J Med Inform. 2006;75:513-29.

24. Robu I. Semantic Web applications in the biomedical field. Journal of the EAHIL. 2008 Feb [cited 2008 Feb 24];4(1): 3942. Available from http://www.eahil.net/newsletter/journal_ 2008_vol4_n1.pdf.

25. McCathie-Nevile J, Méndez E. Library cards for the 21st Century. Catalog Class Q. 2007;43(3/4):21-45.

26. Legg C. Ontologies on the Semantic Web. In: Cronin B, editor. ARIST. 2007;41:432-3.

27. Miles A, Pérez-Agüera J. SKOS: simple knowledge organisation for the Web. Catalog Class Q. 2007;43(3/4):69-83.

28. Graves M, Constabaris A, Brickley D. FOAF: Connecting people on the Semantic Web. Catalog Class Q. 2007;43(3/4):191-202.

29. Greenberg J, Mendez E. Toward a more library-like Web via semantic knitting. Catalog Class Q. 2007;43(3/4):1-8.

30. Golbeck J, Rothstein M. Linking Social Networks on the Web with FOAF. WWW2008, 2008 April 21-25; Beijing, China [cited 2008 Feb 24]. Available from http://www.slimtoolbar.com/ $\sim$ golbeck/downloads/foaf.pdf.

31. Joint Steering Committee (JSC) for Development of RDA (Resource Description and Access). Collections Canada. Prospectus documents [cited 2008 Feb 24]. Available from http://www.collectionscanada.gc.ca/jsc/index.html.

32. Coyle K, Hillmann D. Resource Description and Access (RDA). D-Lib Magazine. 2007;13(1/2):1082.

33. Lyndenberg HM. John Shaw Billings: creator of the National Medical Library, and its catalogue. Chicago: American Library Association; 1924.
34. Marshall C, Shipman, F. Which Semantic Web? Proc ACM Hypertext. 2003 [cited 2008 Feb 24]. Available from http://www.csdl.tamu.edu/ marshall/ht03-sw-4.pdf.

35. Borland J. A smarter Web. Tech Rev. 2007 Mar/Apr [cited 2008 Feb 24]. Available from http://www.technologyreview.com/ http://www.technologyreview.com/

36. Styles R, Ayers D, Shabir N. Semantic MARC, MARC 21, and the Semantic Web. Proceedings of WWW. 2008 Jan 27 [cited 2008 Feb 24]. Available from http://www.dynamicorange.com/ blog/archives/Semantic\%20Marcup.pdf.

37. Hillman D. Great leaps forward. Technicalities. 2007;27(4):10-3.

38. Hillman D. Structures and standards for our bibliographic future. Presentation given May 9, 2007 at the Chicago hearing of the Library of Congress Working Group on the Future of Bibliographic Control [cited 2008 Feb 24]. Available from http://ecommons.library.cornell.edu/handle/1813/7576.

39. Post LJG, Roos M, Marshall MS, van Driel R, Breit, TM. A Semantic Web approach applied to integrative bioinformatics experimentation: a biological use case with genomics data Bioinformatics. 2007 Sep 19 [cited 2008 Feb 24]. Available from http://bioinformatics.oxfordjournals.org/cgi/content/abstract /btm461v1.

40. Ankolekar A, Krötzsch M, Tran T, Vrandecic D. The two cultures: mashing up Web 2.0 and the Semantic Web. Proceedings of the 16th International Conference on World Wide Web. 2007 [cited 2008 Feb 24]; Banff, Alberta. Available from http://portal. acm.org/citation.cfm?id=1242572.1242684.

41. Michon J. Biomedicine and the Semantic Web: a knowledge model for visual phenotype. Catalog Class $Q$. 2007;43(3/4):149-60.

42. Robu I, Robu V, Thirion B. An introduction to the Semantic Web for health sciences librarians. J Med Libr Assoc. 2006 Apr;94(2):198-205.

43. WikiProteins [homepage on the Internet]. 2008 Jan 29 [cited 2008 Feb 24]. Available from http://www.wikiprofessional.com.

44. Tynan D. Five ways to defend your online profile. PC World. 22 Feb 2008 [cited 2008 Feb 24]. Available from http://www.pcworld.com/article/id,142721-c,internetnetworking/ article.html.

45. Giustini D. How Google is changing medicine. BMJ. 2005;331:1487-8.

46. Tang H, Ng JHK. Googling for a diagnosis: use of Google as a diagnostic aid: an internet-based study. BMJ. 2006;333:1143-5.

47. Book of Joe [weblog]. The Deep Web: 'size matters' [cited 2008 Feb 24]. Available from http://www.bookofjoe.com/ 2008/01/the-deep-web-si.html.

48. O'Looney J. Social work and the new semantic information revolution. Admin Soc Work. 2005;29(4): 5-34. 
This article has been cited by:

1. Allison McArthur. 2009. Health information professionals and the Semantic Web: a symbiotic relationship?. Journal of the Canadian Health Libraries Association 30:3, 81-84. [Abstract] [PDF] [PDF Plus] 